\title{
Risk assessment of musculoskeletal disorders by OVAKO Working posture Analysis System OWAS and evaluate the effect of ergonomic training on posture of farmers
}

\author{
Beheshti MH, $\mathrm{MSc}^{1}$, Firoozi chahak A, MSc ${ }^{1}$, Alinaghi Langari AA, MSc ${ }^{2}$, Poursadeghiyan \\ $\mathrm{M}, \mathrm{PhD}^{3}$ \\ 1- Faculty Member, Dept. of Occupational Health, Faculty of Health, Gonabad University of Medical Sciences, Gonabad, \\ Iran. 2- Faculty Member, Dept. of Occupational Health, Faculty of Health, Bam University of Medical Sciences, Bam, Iran. \\ 3- Faculty Member, Dept. of Ergonomics, School of Rehabilitation, Social Determinants of Health Research Center, \\ University of Social Welfare and Rehabilitation Sciences, Tehran, Iran.
}

\begin{abstract}
Received: January 2016, Accepted: April 2016

Background: The agricultural sector is one of the most important sectors in production. The safety and health of farmers are important factors that can cause a significant increase in efficiency and productivity. The aim of this study was the assessment of musculoskeletal disorders (MSDs) using the OVAKO Working Posture Analysis System (OWAS) and evaluation of the effect of ergonomic training on posture of farmers.

Materials and Methods: In this study, 400 farms were evaluated in 5 major activities including gathering of pistachios by men, gathering of pistachios by women, spading, gathering of pistachio waste, picking of wheat, and fertilizing regarding MSDs using the Nordic Musculoskeletal Questionnaire (NMQ) and OWAS. Then, the required ergonomic training was presented as face-toface to farmers and again evaluation was performed after the intervention.

Results: Low back pain and knee problems had the highest frequency and can be caused by standing or sitting for long periods of time, displacement and manual material handling, and undesirable workstations. A significant relationship was found between age and work experience, and MSDs ( $\mathrm{P}$ 0.001). Risk level in pistachio and wheat gathering tasks was lowered significantly after the ergonomic interventions and required training compared to before the intervention ( $\mathrm{P}$ 0.050). However, no significant change was observed in the spading and fertilizing tasks.

Conclusions: The results showed that the prevalence of MSDs was relatively high in the studied farmers. Moreover, the level of risk that was obtained according to the OWAS indicated that the working conditions and environment in this industry are harmful. Therefore, taking corrective actions in order to improve the working conditions is necessary.
\end{abstract}

Keywords: Posture, Assessments, Farmers, Musculoskeletal Diseases

\section{Introduction}

Human resources are the main survival factor in a system and humans are considered as an integral part of the work environment $(1,2)$. Individuals are affected by harmful factors in their work environments. Exposure to such factors can be the cause of occupational diseases. Musculoskeletal disorders are one of the most common occupational diseases $(3,4)$. In 1989, 6500000 cases of diseases and injuries were reported in America and 5 million individuals suffered from musculoskeletal injuries due to inappropriate working conditions (5). Studies have shown that almost $10 \%$ of occupational accidents are related to the musculoskeletal system and are caused by sudden movements, lifting, repetitive motions, or overuse of body organs. It is estimated that in Europe 4000000 worker suffer from work-related musculoskeletal disorders (WMSDs) (more than 30\% of

\footnotetext{
* Corresponding author: Ali Firoozi chahak, Dept. of Occupational Health, Faculty of Health, Gonabad University of Medical Sciences, Gonabad, Iran. Email: ali_firoozi66@yahoo.com
} 
workers) and in America 44\% of work-related diseases is related to the musculoskeletal system (6). One of the important sectors in production is the agricultural sector. Occupational health and safety are the most important factors that can increase efficiency and productivity in the agricultural sector (7). The agricultural sector has traditionally lacked the required health facilities, but in recent decades it has been greatly changed and the health and safety of farmers have been improved. However, farmers are exposed to many occupational risk factors, one of which is musculoskeletal disorders (MSDs) in agriculture (8). The International Labour Organization (ILO) estimates that annually 170,000 farmers die due to their occupation, which is more relevant to work with machines and poisons. This means that the risk of death in farming is twice that of other occupations. A study in America showed that $26 \%$ of farmers suffer from back pain, which is related to their occupation (9). MSDs are injuries and diseases of the muscles, tendons, ligaments, joints, nerves, blood vessels, and all structures that are involved in motion. The relationship of these injuries with ergonomic risk factors has been proven. Although these disorders are not often fatal, they result in failure and even permanent disability (9). MSDs are a healthrelated issue and a major cause of disability worldwide (10-12). In America, MSDs are the cause of loss of working time in more than 600,000 workers (13). WMSDs are more common in the hands, wrists, elbows, shoulders, and neck; thus, exposure is studied in these areas of the body $(11,14)$. There are various ergonomic factors in agricultural occupations including non-standard body positions during work, kneeling, curved spine, pressure and torsion in body organs, loading, maintenance activities, inappropriate load lifting, and lack of rest breaks for long periods of time $(15,16)$. Postural analysis can be a strong and effective technique for ergonomic assessment of work activities. Through ergonomic assessment of risks arising from inappropriate body positions, the risk of
WMSDs can be predicted and strategies can be provided to protect workers and increase productivity. An important method of postural assessment is the OVAKO Working Posture Analysis System (OWAS).

In the OWAS method, working status and stress on the musculoskeletal system are identified and then classified in terms of terminology, requirements, and priorities (8). This method was first developed and introduced in Finland and in a steel production company. It should be noted that the inter observer reliability of this method has been reported as $90 \%$ and higher. The comparison of OWAS postural assessment results and SELSPOT system measurement (SELective light SPOT recognition) results shows that OWAS provide correct results about the condition of the body pressure and hence, has acceptable reliability. The aim of this study was to determine the prevalence of MSDs among farmers using the Nordic Musculoskeletal Questionnaire (MNQ) and OWAS.

\section{Material and Methods}

This cross-sectional study was conducted on 400 farmers. Data were collected through interviews and questionnaires. The studied farmers were in rural areas; therefore, after determining the number of villages and providing a list of their villages, 5 villages were selected randomly and, in each village, farmers were randomly selected while working and interviewed. This study conducted using Nordic Musculoskeletal Questionnaire (MNQ) and OWAS methods. OWAS is a postural assessment method that is conducted by encoded posture. This method often evaluates the posture of the back (4 postures), arms (3 postures), and legs (7 postures), and displaced load in the form of 3 items (17). In this study, the work phase was specified through occupational analysis, and in every phase, body posture was sampled and the code corresponding to each posture was registered at regular intervals of 30 to 60 seconds during 
work. Sampling in each work phase lasted 20 to 40 minutes, because each working cycle lasted 20 to 40 minutes. Subsequently, working postures were coded and analyzed. It should be noted that in this study, sampling was performed through photographing postures. The inclusion and exclusion criteria of this study consisted of the willingness to participate in the project, lack of any diseases and MSDs, and at least one year of work experience. In ergonomic assessment of farmers' tasks, 5 major tasks including gathering of pistachios by men, gathering of pistachios by women, spading, gathering of pistachio waste, picking of wheat, and fertilizing were evaluated using OWAS and NMQ. Some examples of the physical conditions of farmers are illustrated in figure 1.
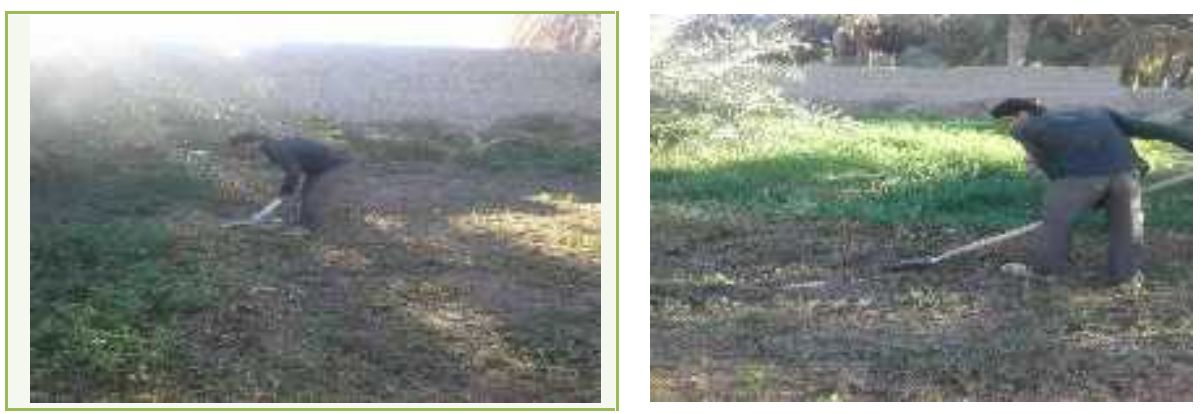

Figure 1: Some of the physical conditions of farmers

On the other hand, the NMQ is a useful tool in determining the symptoms of MSDs, which were read and explained to the subjects by the researcher. In this study, to determine the effect of ergonomics principles training on workers posture, training courses were held as lectures, and then, workers' postures were evaluated.

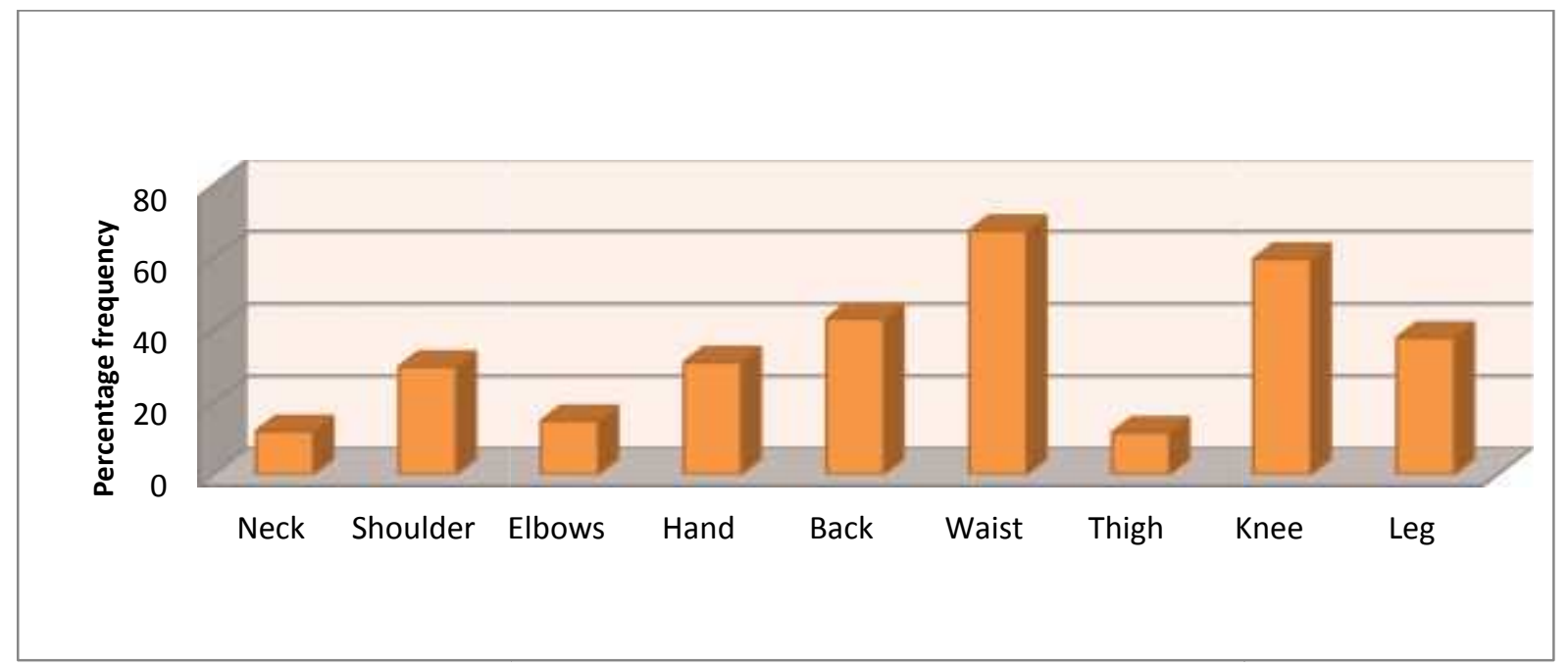

Figure 2: Prevalence of musculoskeletal disorders in different body parts during 12 months using the Nordic Musculoskeletal Questionnaire

\section{Results}

Figure 2 shows the frequency of MSDs in the period of 12 months in different parts of the body. As can be seen in the charts, low back pain and knee problems had the highest frequency. These issues are caused by standing or sitting for a long period of time, displacement and manual material handling, and undesirable workstations. According to figure 2, the highest frequency of MSDs was observed in the waist and knees. Among individuals with work experience of over 20 years, $13 \%$ to $67 \%$ frequency of pain in these 
areas was reported, while in subjects with less than 9 years of experience, the frequency of pain in the abovementioned areas varied from $2 \%$ to $28 \%$ (Table 1 ).

Table 1: The relationship between pain in different organs of the body and work experience during 3 months and 12 months before completing the questionnaire

\begin{tabular}{|c|c|c|c|c|c|c|c|}
\hline \multirow{2}{*}{$\begin{array}{l}\text { Work } \\
\text { experience }\end{array}$} & \multicolumn{2}{|c|}{ Less than 9 years } & \multicolumn{2}{|c|}{ 20-10 years } & \multicolumn{2}{|c|}{ More than 20 years } & \multirow[b]{2}{*}{ P-Value } \\
\hline & Frequency & $\begin{array}{l}\text { Percentage } \\
\text { Frequency }\end{array}$ & Frequency & $\begin{array}{l}\text { Percentage } \\
\text { Frequency }\end{array}$ & Frequency & $\begin{array}{l}\text { Percentage } \\
\text { Frequency }\end{array}$ & \\
\hline Neck pain (3 months) & 20 & 16.1 & 40 & 22.7 & 42 & 42 & 0.001 \\
\hline Neck pain (12 months) & 19 & 15.3 & 40 & 22.7 & 42 & 42 & 0.001 \\
\hline Back pain (3 months) & 8 & 6.5 & 19 & 10.8 & 24 & 24 & 0.001 \\
\hline Back pain (12 months) & 7 & 5.6 & 19 & 10.8 & 25 & 25 & 0.001 \\
\hline Back pain (3 m onths) & 34 & 27.4 & 104 & 59.1 & 63 & 63 & 0.001 \\
\hline Pain (12 months) & 35 & 28.2 & 105 & 59.7 & 63 & 63 & 0.001 \\
\hline Hip pain (3 months) & 3 & 2.4 & 11 & 6.3 & 14 & 14 & 0.003 \\
\hline Hip pain (12 months) & 3 & 2.4 & 11 & 6.3 & 13 & 13 & 0.007 \\
\hline Knee pain (3 months) & 33 & 26.6 & 87 & 49.4 & 67 & 67 & 0.001 \\
\hline Knee pain (12 months) & 32 & 25.8 & 87 & 49.4 & 67 & 67 & 0.001 \\
\hline Ankle pain (3 months) & 11 & 8.9 & 30 & 17 & 25 & 25 & 0.005 \\
\hline Ankle pain (12 months) & 11 & 8.9 & 13 & 17 & 26 & 26 & 0.003 \\
\hline
\end{tabular}

The data presented in table 2 indicate that the frequency of pain in various body parts in individuals with short stature (less than 160 $\mathrm{cm})$ was higher than individuals with height of over $160 \mathrm{~cm}$, but this difference was statistically significant only in the neck and knees $(\mathrm{P}<0.050)$.

Table 2: The relationship between pain in different body parts and height during 3 months and 12 months before completing the questionnaire

\begin{tabular}{|c|c|c|c|c|c|c|c|}
\hline \multirow[b]{2}{*}{ Body part } & \multicolumn{2}{|c|}{ Less than $160 \mathrm{~cm}$} & \multicolumn{2}{|c|}{$160-170 \mathrm{~cm}$} & \multicolumn{2}{|c|}{ More than $170 \mathrm{~cm}$} & \multirow[b]{2}{*}{ P-Value } \\
\hline & Frequency & $\begin{array}{l}\text { Percentage } \\
\text { Frequency }\end{array}$ & Frequency & $\begin{array}{l}\text { Percentage } \\
\text { Frequency }\end{array}$ & Frequency & $\begin{array}{l}\text { Percentage } \\
\text { Frequency }\end{array}$ & \\
\hline Neck pain (3 months) & 48 & 36.1 & 36 & 20.5 & 18 & 19.8 & 0.003 \\
\hline Neck pain (12 months) & 46 & 34.6 & 37 & 21 & 18 & 19.8 & 0.010 \\
\hline Back pain (3 months) & 15 & 11.3 & 21 & 11.9 & 15 & 16.5 & 0.471 \\
\hline Back pain (12 months) & 16 & 12 & 20 & 11.4 & 15 & 16.5 & 0.471 \\
\hline Back pain (3 months) & 77 & 57.9 & 84 & 47.7 & 40 & 44 & 0.082 \\
\hline Pain (12 months) & 77 & 57.9 & 86 & 48.9 & 40 & 44 & 0.098 \\
\hline Hip pain (3 months) & 13 & 9.8 & 10 & 5.7 & 5 & 5.5 & 0.307 \\
\hline Hip pain (12 months) & 13 & 9.8 & 10 & 5.7 & 4 & 4.4 & 0.217 \\
\hline Knee pain (3 months) & 74 & 55.6 & 69 & 39.2 & 44 & 48.4 & 0.015 \\
\hline Knee pain (12 months) & 74 & 55.6 & 69 & 39.2 & 43 & 47.3 & 0.016 \\
\hline Ankle pain (3 months) & 20 & 15 & 31 & 17.6 & 15 & 16.5 & 0.833 \\
\hline Ankle pain (12 months) & 20 & 15 & 32 & 18.2 & 15 & 16.5 & 0.762 \\
\hline
\end{tabular}

Results of chi-square test showed that body weight had no statistically significant correlations with pain in the neck, back, hips, knees, and ankles in the last 3 and 12 months $(\mathrm{P}>0.050)$ (Table 3$)$. The only significant relationship was observed in the back. The relationship between demographic variables and MSDs is provided in table 4. As can be seen, average age and work experience in individuals with MSDs was higher than individuals who did not report symptoms of MSDs. 
Table 3: The relationship between pain in different body parts and weight during 3 months and 12 months before completing the questionnaire

\begin{tabular}{|c|c|c|c|c|c|c|c|}
\hline \multirow[b]{2}{*}{ Body part } & \multicolumn{2}{|c|}{ Less than $59 \mathrm{~kg}$} & \multicolumn{2}{|c|}{$59-70 \mathrm{~kg}$} & \multicolumn{2}{|c|}{ More than $70 \mathrm{~kg}$} & \multirow[b]{2}{*}{ P-Value } \\
\hline & Frequency & $\begin{array}{l}\text { Percentage } \\
\text { Frequency }\end{array}$ & Frequency & $\begin{array}{l}\text { Percentage } \\
\text { Frequency }\end{array}$ & Frequency & $\begin{array}{l}\text { Percentage } \\
\text { Frequency }\end{array}$ & \\
\hline Neck pain (3 months) & 36 & 24.52 & 50 & 28.2 & 16 & 21.1 & 0.455 \\
\hline Neck pain (12 months) & 35 & 23.8 & 50 & 28.2 & 16 & 21.1 & 0.424 \\
\hline Back pain (3 months) & 28 & 19 & 18 & 10.2 & 5 & 6.6 & 0.012 \\
\hline Back pain (12 months) & 27 & 18.4 & 19 & 10.7 & 5 & 6.6 & 0.025 \\
\hline Back pain (3 months) & 73 & 49.7 & 91 & 51.4 & 37 & 48.7 & 0.909 \\
\hline Pain (12 months) & 75 & 51 & 91 & 51.4 & 37 & 48.7 & 0.921 \\
\hline Hip pain (3 months) & 12 & 8.2 & 11 & 6.2 & 5 & 6.6 & 0.781 \\
\hline Hip pain (12 months) & 11 & 7.5 & 11 & 6.2 & 5 & 6.6 & 0.901 \\
\hline Knee pain (3 months) & 70 & 47.6 & 82 & 46.3 & 35 & 46.1 & 0.965 \\
\hline Knee pain (12 months) & 69 & 46.9 & 82 & 46.3 & 35 & 46.1 & 0.990 \\
\hline Ankle pain (3 months) & 23 & 15.6 & 29 & 16.4 & 14 & 18.4 & 0.868 \\
\hline Ankle pain (12 months) & 23 & 15.6 & 30 & 16.9 & 14 & 18.4 & 0.868 \\
\hline
\end{tabular}

Number of observations concerning the tasks of pistachio gathering by men, pistachio gathering by women, spading, gathering of pistachio waste, picking of wheat, and fertilizing were $601,401,201,201,201$, and 101 , respectively. Results of posture analysis and risk assessment using OWAS according to task type are shown in figure 3.

Table 4: The relationship between musculoskeletal disorders and demographic variables

\begin{tabular}{cccccc}
\hline \multirow{2}{*}{ Variable } & \multicolumn{2}{c}{$\begin{array}{c}\text { Presence of musculoskeletal } \\
\text { disorders }\end{array}$} & \multicolumn{2}{c}{$\begin{array}{c}\text { Lack of musculoskeletal } \\
\text { disorders }\end{array}$} & \multirow{2}{*}{ P-Value } \\
\cline { 2 - 5 } & Mean & SD & Mean & SD & \\
\hline Age (years) & 43.76 & 13.7 & 31.42 & 8.6 & $<0.001$ \\
\hline Weight (kg) & 62.65 & 9.5 & 63.75 & 7.8 & $<0.872$ \\
\hline Height (cm) & 165.63 & 8.4 & 163.87 & 7.8 & $<0.651$ \\
\hline $\begin{array}{c}\text { Work experience } \\
\text { (years) }\end{array}$ & 13.8 & 6.5 & 8.8 & 4.3 & $<0.001$ \\
\hline
\end{tabular}

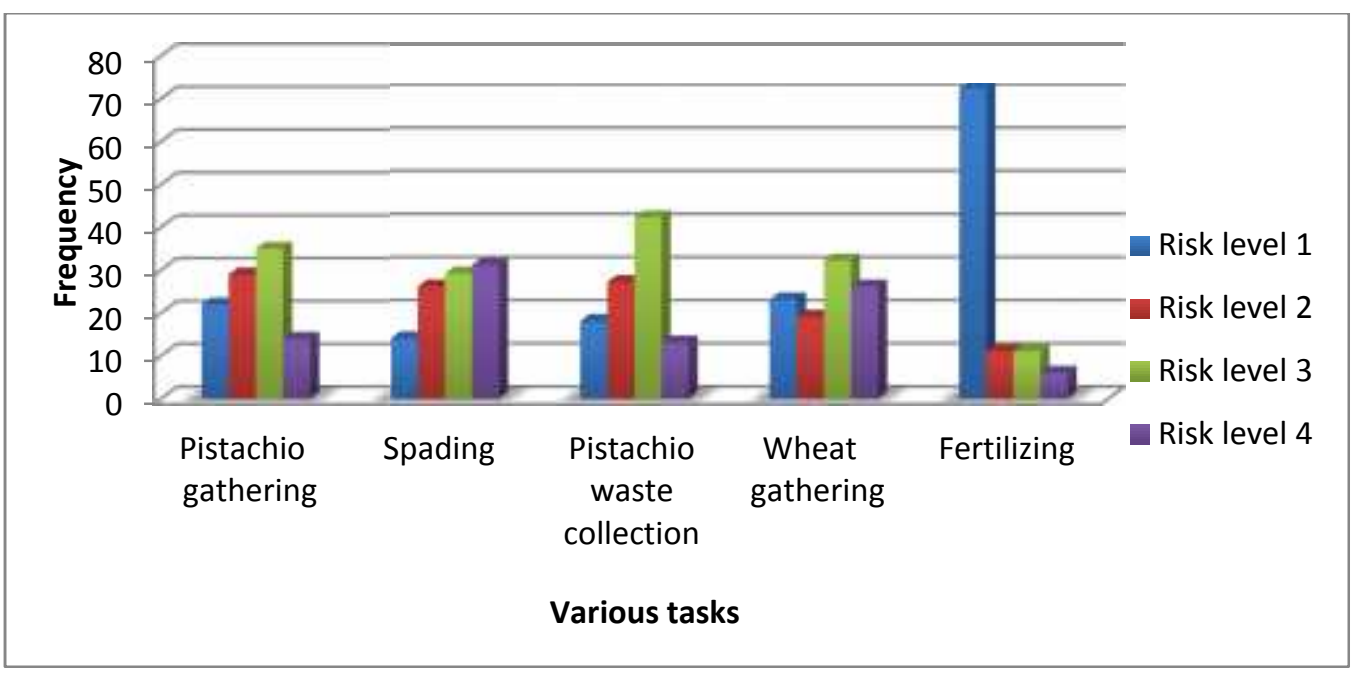

Figure 3: Ergonomic risk level of musculoskeletal disorders in a variety of agricultural tasks based on OWAS method 


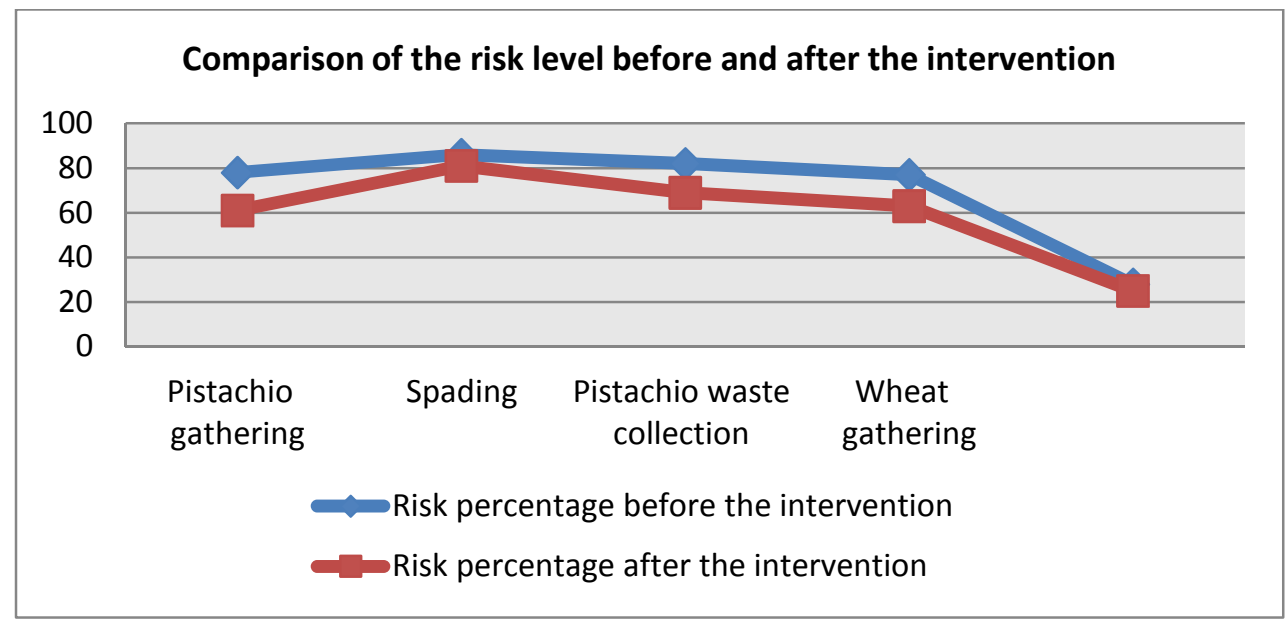

Figure 4: Comparison of the risk level before and after the intervention

Figure 4 shows the total risk level (risk levels 1-4) before and after ergonomic interventions and necessary training in the studied tasks.

As shown in figure 3 , the highest percentage of normal posture was allocated to the task of fertilizing (72\%), although a harmful or very harmful posture was observed in this task. In wheat gathering, $77 \%$ of the body posture observed was harmful and only 23\% was normal. Pistachio gathering was the single task performed by women. Posture analysis and risk assessment results of men and women in pistachio gathering according to OWAS are shown in figure 5. In pistachio gathering, women's postures were better and more natural than men.

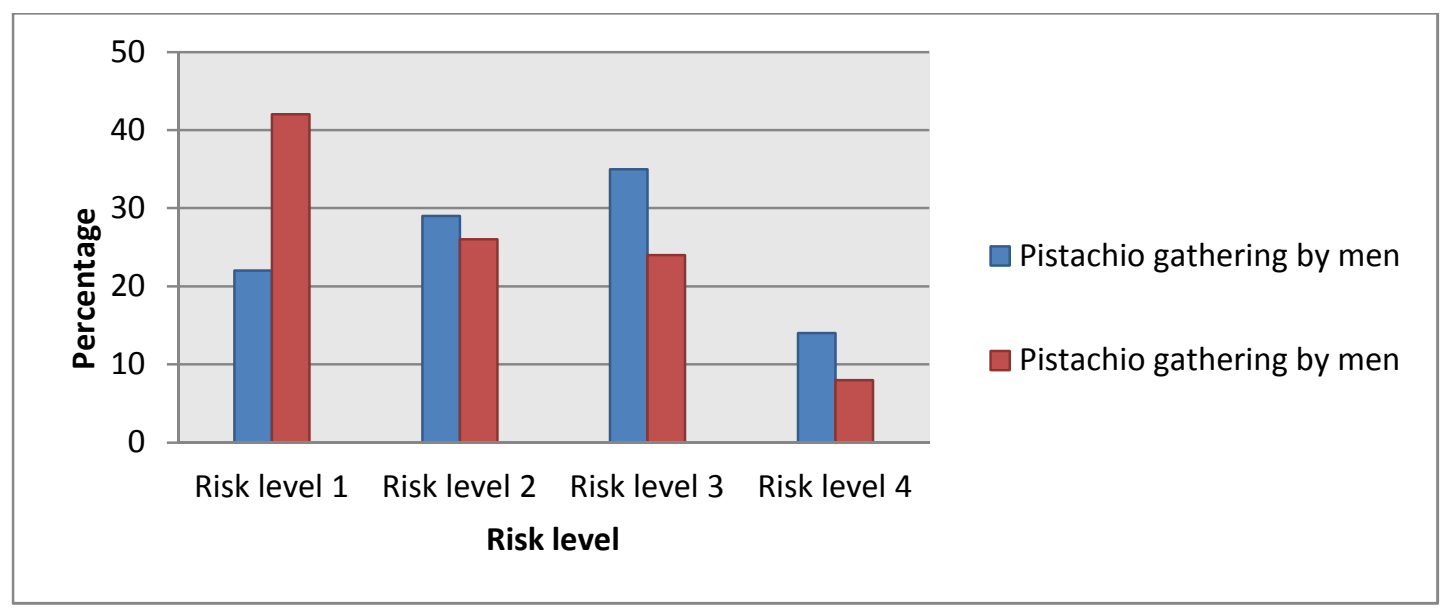

Figure 5: Posture analysis and risk assessment results of men and women in pistachio gathering according to OWAS

\section{Discussion}

The aim of this study was to evaluate the ergonomic risk of MSDs and investigate the effect of ergonomic interventions and 8 weeks of training on exposure to them. As shown in table 1, pain in the neck, back, waist, hips, knees, and ankles during the 3 months or 12 months of completing the questionnaire increased significantly with increase in work experience $(\mathrm{P}<0.050)$. There was a significant relationship between age and work experience, and the prevalence of MSDs ( $\mathrm{P}$ 0.001). Before the intervention, in the pistachio gathering tasks, $78 \%$ of working posture was in risk levels 2,3 , and 4 . This frequency was reduced to $61 \%$ after the intervention. In addition, this reduction was observed in pistachios and wheat gathering tasks. It should be noted that risk levels 1, 2, 3, 
and 4 are, respectively, natural posture, stressful posture, harmful posture, and very harmful posture.

The results showed that agricultural tasks, due to the nature of the work and hazardous occupational factors, are considered as traumatic tasks; so that during the 12 months of the study, $83.56 \%$ of the subjects presented symptoms of MSDs in at least 1 of the 9 studied body parts. Based on the NMQ and report of the studied farmers, MSDs had the highest prevalence in the back and knees. This can be due to poor posture or static activity that is commonly observed in various tasks such as harvesting and pistachios gathering. This means that attention to risk factors related to these areas and their elimination can be an important step in improving the working conditions and the preventing MSDs. Moreover, prevention programs should focus on controlling the risk factors related to these areas. In the study performed by Ismailian et al. in Tehran Tile Factory, the most important problems reported were inappropriate access and working height (18). The results showed that age and work experience have significant relationships with the occurrence of MSDs and this finding is in agreement with other studies (19-21).

In this study, no relationship was found between MSDs, and height and weight. This result also proves the effect of occupational factors on ergonomic injuries $(22,23)$. The results showed that $25.3 \%$ of the subjects had neck pain that was similar to the results of study by Joh Nrosecrance on MSDs in farmers in Kansas, America (24). The results of this study were lower than that of the study by Afifehzadeh-Kashani et al. in surgeons and surgical residents of Shiraz University of Medical Sciences, Iran (25). The risk level was higher in wheat gathering and pistachio collecting tasks, in which most of the movement is static, compared to other tasks. Risk level in pistachio and wheat gathering tasks was lowered significantly after the ergonomic interventions and required training compared to before the intervention $(\mathrm{P}$
0.050). Nevertheless, no significant change was observed in spading and fertilizing tasks. This illustrates that taking corrective measures in these tasks should be prioritized in ergonomics intervention programs. The results of this study showed that $46.4 \%$ of subjects experienced pain and discomfort in the knees and this prevalence was lower than that reported by Farhad Ghamari et al. in an ergonomic assessment of bakers in Arak, Iran (26).

\section{Conclusion}

The results of this assessment showed that in various agricultural activities, farmers' postures were different and each one had a different ergonomic risk level. It can be concluded that the prevalence of MSDs in agriculture is relatively high. Furthermore, the level of risk that was obtained based on OWAS indicates the presence of traumatic conditions and working environment in this industry. Hence, taking corrective measures to improve working conditions is essential.

\section{Acknowledgments}

The authors are grateful to faculty members of the Department of Occupational Health at Gonabad University of Medical Sciences, Iran, and all managers and farmers who helped us in this project.

Conflict of interests: None declared.

\section{Reference}

1. Dehghan Nayeri N, Nazari AA, Salsali M, Ahmadi F, Adib Hajbaghery M. Iranian staff nurses' views of their productivity and management factors improving and impeding it: a qualitative study. Nurs Health Sci 2006; 8(1):51-6.

2. Roman-Liu D. Comparison of concepts in easy-to-use methods for MSD risk assessment. Appl Ergon 2014; 45(3):420-7.

3. Bernal D, Campos-Serna J, Tobias A, Vargas-Prada S, Benavides FG, Serra C. Work-related psychosocial risk factors and musculoskeletal disorders in hospital nurses and nursing aides: a systematic review and 
meta-analysis. Int $\mathrm{J}$ Nurs Stud 2015; 52(2):635-48

4. Choobineh A, Lahmi M, Hosseini M, Khani Jazani R, Shahnavaz H. Musculoskeletal problems in Iranian hand-woven carpet industry in Iran. Journal of School of Public Health and Institute of Public Health Research 2004; 2(3):9-24.

5. Salvendy G. Handbook of human factors and ergonomics. $4^{\text {th }}$ ed. Hoboken, New Jersey, United States of America: John Wiley \& Sons, Inc; 2012.

6. Hoe VC, Urquhart DM, Kelsall HL, Sim MR. Ergonomic design and training for preventing work-related musculoskeletal disorders of the upper limb and neck in adults. Cochrane Database Syst Rev 2012; (8):CD008570. doi: 10.1002/14651858.CD008570.pub2.

7. Choobineh AR, Soleimani E, Daneshmandi $\mathrm{H}$, Mohamadbeigi A, Izadi KH. Prevalence of musculoskeletal disorders and posture analysis using RULA method in Shiraz general dentists in 2010. Journal of Islamic Dental Association of Iran 2012; 24(4):24450.

8. Razavi Asl MH, Ezatian R. Occupational health in agirculture. $1^{\text {st }}$ ed. Qom: Andisheh Mandegar Publisher; 2006. P.7-8.

9. Saremi M, Lahmi MA, Faghihzadeh S. The effects of ergonomic intervention on musculoskeletal disorders among dentists. Daneshvar Medicine 2006; 13(64):55-62.

10. Dehghan N, Choobineh AR, Hasanzadeh J. Interventional ergonomic study to correct and improve working postures and decrease discomfort in assembly workers of an electronic industry. Iran Occupational Health 2013; 9(4):70-9.

11. Hwang J, Kong YK, Jung MC. Posture evaluations of tethering and loose-housing systems in dairy farms. Appl Ergon 2010; 42(1):1-8.

12. Bhuse PK, Vyavahare RT. Ergonomic Evaluation of Knapsack Sprayer used in Agricultural Application. Int J Sci Eng Res 2014; 5(12):903-7.

13. Mostaghaci M, Salimi Z, Javaheri M, Hoseininejad S, Salehi M, Davari M, et al. Evaluation of the musculoskeletal disorders and its risk factors in the workers of an agricultural equipment-manufacturing plant. Occupational Medicine Quarterly Journal 2012; 3(3):19-25.

14. Nakhaei M, FaragZadeh $Z$, Tabiei Sh, Saadatjoo SA, Mahmoodi Rad Gh, Hoseini MH. Evaluation of ergonomic position during work in nurses of medical and surgical wards in Birjand University of Medical Sciences hospitals. Journal of Birjand University of Medical Sciences 2006; 13(2):9-15.

15. Cortina LM, Magley VJ. Raising voice, risking retaliation: Events following interpersonal mistreatment in the workplace. J Occup Health Psychol 2003; 8(4):247-65.

16. Swangnetr $M$, Namkorn $P$, Phimphasak $C$, Saenlee K, Kaber D, Buranruk O, et al. Ergonomic analysis of rice field plowing. $1^{\text {st }}$ ed. Boca Raton FA, USA: CRC Press LLC; 2012. Chapter 64, Advances in Physical Ergonomics and Safety. P.565-74.

17. Choobineh AR. Methods of posture assessment in the occupational ergonomics. Hamadan: Fanavaran; 2004. P.79-96.

18. Kelishadi R, Razaghi EM, Gouya MM, Ardalan G, Gheiratmand R, Delavari A, et al. Association of physical activity and the metabolic syndrome in children and adolescents: CASPIAN Study. Horm Res 2007; 67(1):46-52.

19. Burdorf A, Sorock G. Positive and negative evidence of risk factors for back disorders. Scand J Work Environ Health 1997; 23(4):243-56.

20. Salaffi F, De Angelis R, Grassi W; MArche Pain Prevalence; INvestigation Group (MAPPING) study. Prevalence of musculoskeletal conditions in an Italian population sample: results of a regional community-based study. I. The MAPPING study. Clin Exp Rheumatol 2005; 23(6):81928.

21. Choobineh AR, Mokhtarzadeh A, Salehi M, Tabatabaei SHR. Ergonomic evaluation of exposure to musculoskeletal disorders risk factors by QEC technique in a rubber factory. Jundishapur Scientific Medical Journal 2008; 7(1):46-55.

22. Punnett L, Wegman DH. Work-related musculoskeletal disorders: the epidemiologic evidence and the debate. J Electromyogr Kinesiol 2004; 14(1):13-23.

23. Tayyari F, Smith JL. Occupational ergonomics: principles and applications (Manufacturing Systems Engineering Series). United Kingdom: Chapman \& Hall London; 1997.

24. Douphrate DI, Rosecrance JC, Stallones L, Reynolds SJ, Gilkey DP. Livestock-handling injuries in agriculture: An analysis of Colorado workers' compensation data. Am J Ind Med 2009; 52(5):391-407.

25. Afifehzadeh-Kashani $\mathrm{H}$, Choobineh $\mathrm{A}$, Bakand S, Gohari M, Abbastabar H, Moshtaghi P. Validity and reliability farsi version Cornell Musculoskeletal Discomfort Questionnaire (CMDQ). Iran Occupational Health Journal 2011; 7(4):10-0.

26. Ghamari F, Mohammadbeigi A, Khodayari M. Work stations revision by ergonomic posture analyzing of Arak bakery workers. The Scientific Journal of University of Medical Sciences 2010; 18(70):80-90. 